\title{
Providing special vehicles with spare parts in oil- and-gas sector
}

\author{
Bauer Vladimir Ioganesovich \\ Dept. of Automobiles and Technological Machines Service \\ Tyumen Industrial University \\ Tyumen, Russia \\ vjbauer@mail.ru
}

\author{
Mukhortov Aleksandr Alekseevich \\ Head of Social Development Department \\ Transneft Siberia, JSC \\ Tyumen, Russia
}

\begin{abstract}
In the paper, the methodology of creating a rational system of providing special vehicles, operating in the oil-andgas sector, with spare parts is presented. As a result of the study, the criteria of effectiveness of providing with spare parts were determined. The method of rational distribution of spare parts among the elements of the production and technical base engaged in servicing and repairing special vehicles, was developed. The algorithms and the mathematical apparatus, presented in the paper, allow determining the nomenclature of spare parts depending on the parameters of operating time of special vehicles and the rate of their failures. The elements of the production and technical base were classified: sites of servicing and maintenance of machinery in the deposit, transport depots of machinery in large cities, specialised enterprises engaged in capital repairs of parts and assemblies. The variants of provision with spare parts by the proposed criteria were compared. By the example of a special vehicle cementing truck "TSA-320", the rate of failures was calculated, the list of the required spare parts is formed, as well as the fund of spare parts was distributed over elements of the production and technical base.
\end{abstract}

Keywords - special vehicles, oil-and-gas sector, exploitation intensity, failure rate, parts nomenclature, stock level

\section{INTRODUCTION}

Servicing oil-and-gas deposits of Western Siberia implies the use of tens of thousands of units of specialised rolling-stock (SRS) and special vehicles (SV). The operation of the machinery for servicing new deposits, distant from the centres of motor transport infrastructure, forces to create temporal bases for servicing and repairing the machinery near production objects being serviced. As a rule, highly repetitive kinds of maintenance service and repairs on replacement of high-wear parts are performed. The most labour-consuming kinds of maintenance service of the machinery, difficult repairs requiring the replacement of basic parts and complex adjustments are conducted as a rule on the main bases of enterprises; capital repairs - at specialised overhaul plants. Periodicity and the list of operations on servicing and repair are regulated by the plant - a manufacturer of machinery; corrected by the regulations

\author{
Kozin Evgeniy Sergeevich \\ Dept. of Automobiles and Technological Machines Service \\ Tyumen Industrial University \\ Tyumen, Russia \\ eskozin@mail.ru
}

Bazanov Artyom Vladimirovich

Dept. of Automobiles and Technological Machines Service

Tyumen Industrial University

Tyumen, Russia

artyom777@mail.ru

of the organisation, exploiting the machinery depending on the conditions of operation. An essential role in provision of effectiveness of maintenance is played by the idle time of machinery when waiting for necessary parts and components. The presence of the full nomenclature of spare parts immediately on the elements of the production and technical base (PTB), on the one hand, reduces the idle time of the machinery, waiting for spare parts. On the other hand, the expenditures, connected with withdrawal of considerable financial resources from circulation, increase. If the availability of all necessary parts on the element of the production and technical base, where corresponding technical work on maintaining or restoration of machinery is conducted, is ensured, the idle time of machinery and their waiting time will approach to zero. It is necessary to determine the required nomenclature and the number of parts and components, periodicity and the volume of supply per element of the production and technical base. And in this case, the number of problems arises. The thing is that the intensity of exploitation of special vehicles in the oiland-gas sector significantly depends on the required volume of works of the main and auxiliary productions and varies substantially throughout a year. Thus, it is necessary to develop a methodological approach, allowing a rational location of spare parts and components among the elements of the production and technological base of enterprises, taking into account the rate of machinery exploitation on the objects of the oil-and-gas sector and the system of existing limitations.

\section{METHODOLOGY}

To solve the tasks of optimizing the location of resources of spare parts and components among the elements of the production and technological base of servicing and repairing special vehicles (SV), it is necessary to identify the criteria of effectiveness and the system of limitations. The overall index, characterising the efficiency of the process of provision the production engaged in maintenance servicing (MS) and repair (R) of SV, is a 
minimum of total expenditures on purchasing and provision of warehouse operations.

In this case, it is necessary to consider main constituents of expenditures as expenditures, connected with provision of purchases of spare parts, expenditures on providing the warehouse operation, expenditures connected with the delivery of spare parts to the place of installation on the vehicle (1). An important condition is reducing the time spent on waiting for spare parts and components in the MS and $\mathrm{R}$ area to the minimum. Let us accept it as a limitation of the optimisation model (2).

$$
\begin{aligned}
E_{\aleph}^{R P}= & E_{\aleph}^{P}+E_{\aleph}^{S}+E_{\aleph}^{E} \rightarrow \min ,(1) \\
& \text { when } T_{\aleph}^{E R P}=0,(2)
\end{aligned}
$$

where $E_{\aleph "}^{R P}$ - total expenditures on providing the MS and $\mathrm{R}$ processes of machinery with spare parts by the $X$ variant of the organisation;

$E_{\aleph}^{P}$ - expenditures on providing the purchases of spare parts by the $N$ variant of the organisation;

$E_{\aleph}^{S}$ - expenditures on providing the operation of the warehouse;

$E_{\aleph}^{E}$ - expenditures on delivery of spare parts to the place of installation on the vehicle;

$T_{\aleph}^{E R P}$ - time of waiting for spare parts by MS and $\mathrm{R}$ stations.

Limitation (2) means that the method, allowing one to form a necessary nomenclature of spare parts and components for each element of the production and technical base (PTB), is necessary. For that, the algorithm of the imitation model (Figure 1) and a mathematical apparatus basing on the use of data about the rate of failures

I - number of failed parts per unit of operating time.

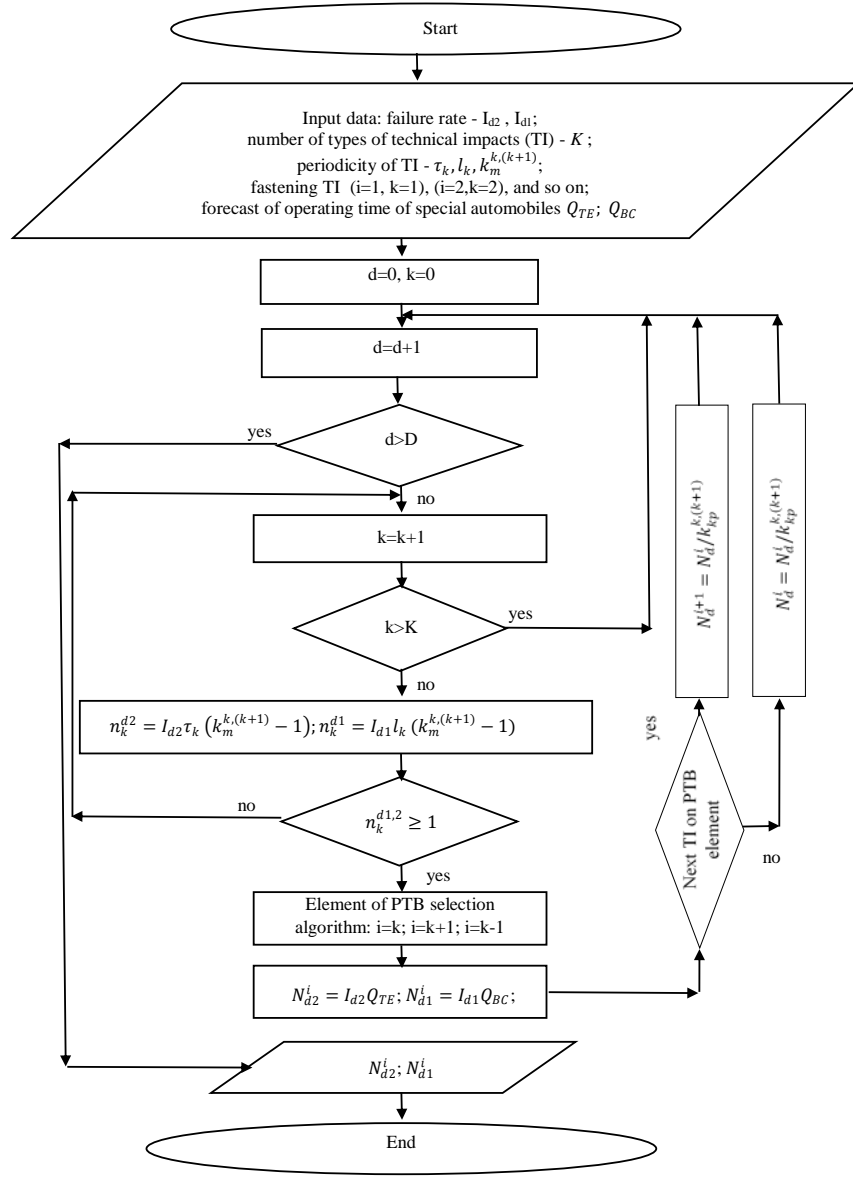

Fig. 1. Generalised algorithm of simulation model of distributing nomenclature of spare parts among PTB elements

A unit of operating time should imply a kilometer of mileage for a base vehicle and a motor hour - for the upper equipment of SV, as well as data on the intensity of machinery exploitation. The exploitation intensity is assumed to be measured by the operating time per time unit. For the base vehicle (BV), it can be mileage per shift, per 24 hours - $Q_{B C}^{D}$, per month - $Q_{B C}^{M}$, per year - $Q_{B C}^{Y}$. For the upper equipment (UE), it is, correspondingly, motor hours per shift, per day - $Q_{T E}^{D}$, per month - $Q_{T E}^{M}$, per year - $Q_{T E}^{Y}$.

The nominal number of spare parts and components, which should be on the i-th element of PTB per predictive period of time, equals the number of parts failures, which are eliminated on the i-th element of PTB for this period of time. How to determine the nomenclature of parts, which must be on the corresponding element of PTB?

Let us suppose that each kind of technical impact (TI) $-\mathrm{k}$ is attached to a certain element of PTB - i, proceeding from economic feasibility.

If the rate of part failures is multiplied by the periodicity of impact by $\mathrm{MS}$ and $\mathrm{R}$, recommended by the plantmanufacturer, and corrected based on the data of machinery exploitation, the predictive number of parts will be obtained per operating time, corresponding to this impact. Let us multiply the obtained value by the ratio of the corresponding kind of TI relatively the impact of the next level. A numeric 
value, which may serve as a criterion for making a decision on location of the part on the element of PTB, will be obtained. If it is more than a unit, this part must be supplied to this element of PTB, to which this TI is attached.

$$
\begin{aligned}
& n_{k}^{d 1}=I_{d 1} l_{k}\left(k_{m}^{k,(k+1)}-1\right), \\
& n_{k}^{d 2}=I_{d 2} \tau_{k}\left(k_{m}^{k,(k+1)}-1\right),
\end{aligned}
$$

where $n_{k}^{d 1}$ - criterion for making decision about location of the part in the place of performing the k-th TI by BV (pcs);

$n_{k}^{d 2}$ - criterion for making decision about location of the part by the place of performing the k-th TI by UE (pcs);

$I_{d 1}$ - failure rate of the $\mathrm{BV}$ part $(\mathrm{pcs} / \mathrm{km})$;

$I_{d 2}$ - failure rate of the BV part (pcs/motor hour);

$l_{k}$ - periodicity of the k-th TI by BV $(\mathrm{km})$;

$\tau_{k}$ - periodicity of the k-th TI by UE (motor hours);

$k_{m}^{k,(k+1)}$ - divisible factor of performing the $\mathrm{k}$-th $\mathrm{TI}$ relatively $\mathrm{k}+1 \mathrm{TI}$.

Depending on the dissipation of random value $I$, variations of intensity of exploitation and the required reliability of logistics, the decision on location of the part on the element of PTB can be made with values $n_{k}^{d 1} ; n_{k}^{d 2}$ being in the range of $0.85 \div 1$. Thus, the nomenclature of spare parts is "linked" to the elements of PTB.

Then let us determine the necessary number of spare parts on each element of PTB. For that, it is necessary to multiply the index of the failure rate by the predictive operating time of machinery for the planned period.

$$
\begin{aligned}
& N_{d 1}^{i}=I_{d 1} Q_{B C}, \\
& N_{d 2}^{i}=I_{d 2} Q_{T E},
\end{aligned}
$$

where $N_{d 1}^{i}$ - number of spare parts of BV for location on the i-th element of PTB;

$N_{d 2}^{i}$ - number of parts of UE for location on the i-th element of PTB; $(\mathrm{km})$;

$Q_{B C}$ - operating time of $\mathrm{BV}$ for the predictive period

$Q_{T E}$ - operating time of UE for the predictive period (motor hour).

It is necessary to approximate the obtained values to the subsequent integer.

The nomenclature, formed in that way, and the number of spare parts by the elements of PTB require correction, related to the fact that in accordance with regulations of the plants-manufacturers of machinery, each succeeding kind of MS and $\mathrm{R}$ requires performance of the operations of the previous stage. Each subsequent stage of MS and R must have one set of the previous stage.

The generalised algorithm of the procedure of formation of rational nomenclature and the number of spare parts by the elements of PTB is given in Figure 1.

\section{RESULTS}

Let us do calculation according to the proposed methodology for UE of SV "TSA-320". The list of TI of UE and their standard periodicity are given in Table 1 . TABLE I. REGULATION KINDS OF TECHNICAL IMPACTS FOR UE OF
SV "TSA-320"

\begin{tabular}{|l|c|ll|}
\hline $\begin{array}{l}\text { Name of } \\
\text { technical impact }\end{array}$ & $\begin{array}{l}\text { Periodicity } \\
\tau_{\boldsymbol{k}} \text { (motor hour) }\end{array}$ & $\begin{array}{l}\text { Divisible } \\
k_{m}\end{array}$ & factor \\
\hline Periodical MS & 50 & 10 \\
\hline Current repairs & 500 & 5 \\
\hline Capital repairs & 2500 & 1 \\
\hline
\end{tabular}

Vehicles operate at a considerable distance from the main production base; therefore, to conduct periodical MS, an element of PTB in the deposit (PM) is organised. The current repairs of UE take place on the base of the enterprise (KS). Capital repairs of UE are conducted on the specialised production (SP). In total, 56 parts, subassemblies, assemblies (PSA) that are to be replaced were determined. All 56 items are distributed in descending order of the failure rate according to Pareto method (Figure 2).

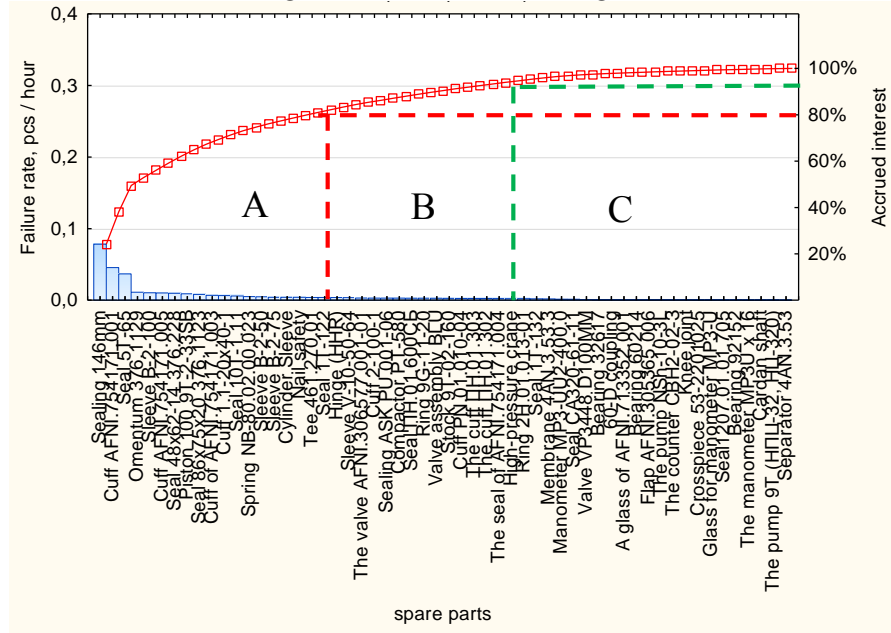

Fig. 2. ABC-analysis of PSA of UE of SV "TSA-320" by failure rate (pcs/motor hour)

Based on this diagram, it is impossible to distribute PSA among the elements of PTB even in case of using recommendations $[1,2,3]$ and conducting $\mathrm{ABC}$-analysis.

In case of applying the mentioned-above algorithm and formula (4), it is possible to link the PSA nomenclature to PTB elements, and then, using formula (6) - to determine the nominal and necessary number for the planned period.

For convenience of representation of the material, 10 most typical items were selected. As a result of long-term observations, the average failure rate by the UE elements was defined (Table 2). 
TABLE II. RESULTS OF DISTRIBUTION OF PSA BY PTB ELEMENTS

\begin{tabular}{|c|c|c|c|c|}
\hline \multirow[t]{2}{*}{ Name of PSA } & \multirow{2}{*}{$\begin{array}{c}\text { Average } \\
\text { failure rate } \\
\text { (pcs/motor } \\
\text { hour) }\end{array}$} & \multicolumn{3}{|c|}{ Value of criterion $n(p c s)$} \\
\hline & & $\begin{array}{l}\text { For } \\
\text { PM }\end{array}$ & $\begin{array}{l}\text { For } \\
\text { KS }\end{array}$ & $\begin{array}{l}\text { For } \\
\text { SP }\end{array}$ \\
\hline Cylinder sleeve & 0.0040661 & 1.83 & 8.13 & 10.16 \\
\hline Safety nail & 0.0040408 & 1.82 & 8.08 & 10.10 \\
\hline Piston 100 9T-2-33SB & 0.0087625 & 3.94 & 17.52 & 21.91 \\
\hline $\begin{array}{l}\text { Valve spring PR52 NB- } \\
80.02 .00 .023\end{array}$ & 0.0049271 & 2.22 & 9.85 & 12.32 \\
\hline Rod cup AFNI.754171.001 & 0.0454203 & 20.44 & 90.84 & 113.55 \\
\hline Shutter AFNI.305365.006 & 0.0005838 & 0.26 & 1.17 & 1.46 \\
\hline $\begin{array}{l}\text { Rotary valve TIP VP3448 } \\
\text { D100MM }\end{array}$ & 0.0008909 & 0.40 & 1.78 & 2.23 \\
\hline Hinged kink & 0.0005322 & 0.24 & 1.06 & 1.33 \\
\hline $\begin{array}{l}\text { Drive shaft of pump drive } \\
\text { 9T }\end{array}$ & 0.0003717 & 0.17 & 0.74 & 0.93 \\
\hline Roller radial bearing & 0.0004016 & 0.18 & 0.80 & 1.00 \\
\hline
\end{tabular}

Using expression (4), the values of criterion $n_{k}^{d 2}$ are obtained for each part, subassembly, assembly (PSA). PSA were distributed among PTB elements according to criteria values. For a better view, PSA related to the base of servicing in the deposit (PM) are coloured in yellow, PSA related to the main production base (KS) - by dark blue, PSA related to specialised production (SP) - by green. Let us note that the parts related to group "B" when using classic ABC-analysis, after being grouped by the proposed method, were included into the group of those to be replaced during PM. From the shortened list, it was a safety nail. From the general list, these were several kinds of sealings (valve sealing 1T-122, sealing of plunger ASK PU. 001-06, etc.).

An important stage of the methodology is predicting the intensity of SV operation by the periods of the year. Specifics of the oil-and-gas sector is such that a precise volume of operation of the machinery is frequently determined after completing works. However, observations conducted for several years allow concluding about the possibility of more precise planning for a month. Figure 3 shows the diagram of changing the intensity of UE operation of SV "TSA-320" in the deposit throughout a year.

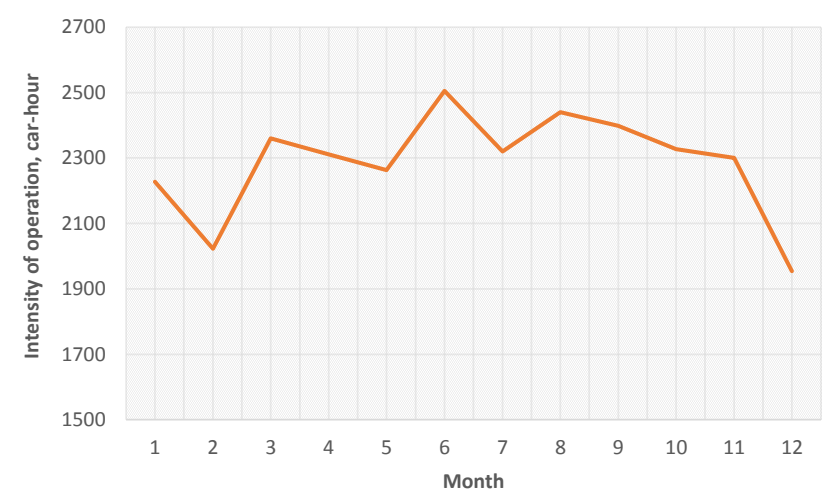

Fig. 3. Change of exploitation intensity of UE of TSA-320 during year in deposit
Based on predictive values of exploitation rate, using expression (6), and the algorithm (Figure 1), the minimal number of parts, which should be present on PTB elements by the beginning of the predictive period was determined (Table 3).

TABLE III. RESULTS OF USING METHODOLOGY ON FORMATION OF RATIONAL NOMENCLATURE AND NUMBER OF DETAILS ON PTB ELEMENTS (FRAGMENT)

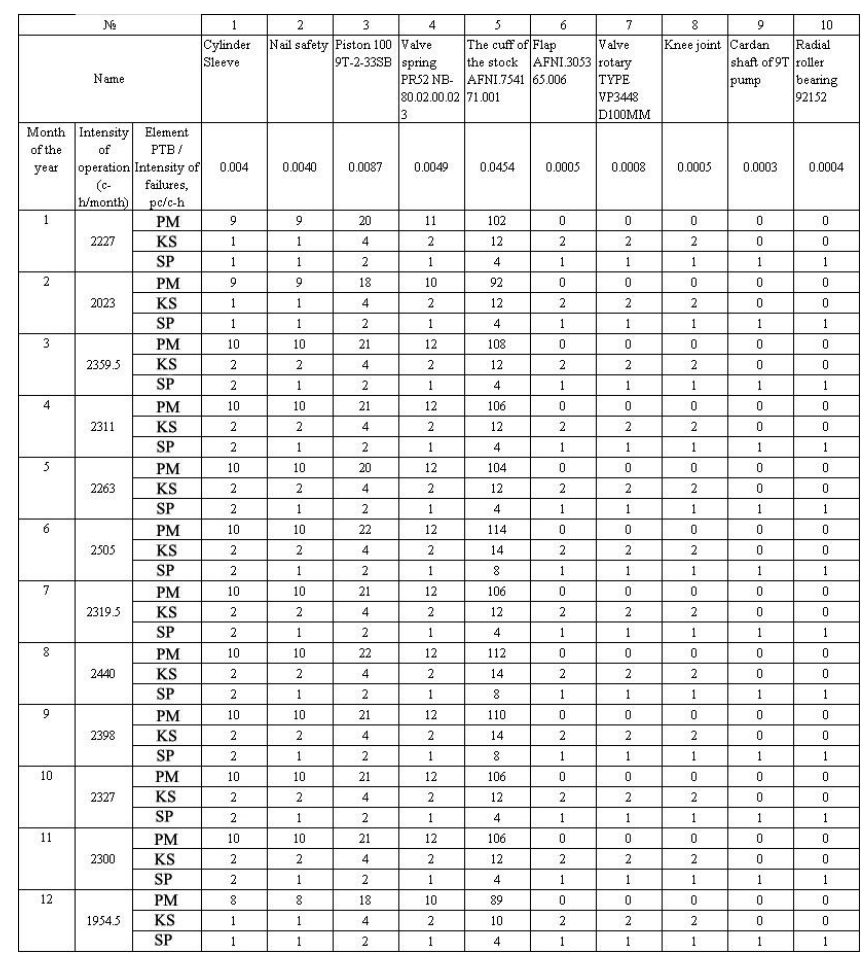

IV. DISCUSSION

The proposed method is a development of the method of $\mathrm{ABC}$-analysis, in accordance with which all parts are divided into 3 groups in descending relevance. ABCanalysis is widely used in different sectors, including for the analysis of warehouses work of service centres' enterprises, operating on the free market of services $[1,2,3,4,5,11]$. However, predicting the need for resources to provide the operation of special vehicles, servicing the oil-and-gas sector, requires a different approach. The thing is that application of modern means of record of machinery operation on the objects of the main production allows maintaining records of not only UE and BA operating time, but also fixing the values of seasonal factors, having a substantial variation under conditions of Western Siberia and exerting significant influence on the failure rate of UE of SV $[6,7,8]$.

A number of works $[6,7]$ are devoted to the problems of study of regularities of influence of seasonality on the failure rate of pieces of SV upper equipment. The obtained dependence of changing the failure rate on ambient temperature allows adjusting the spare parts supply depending on the season and machinery exploitation intensity $[6,8]$. In future, it is necessary to consider a 
mutual use of the methodology [8] and results of the authors' studies for planning the provision by spare parts of distributed PTB by MS and R of SV.

Periodicity of supplying resources is another important aspect of resource provision of any production. It is necessary to determine rational periodicity of delivering spare parts to the PTB elements. The approaches to determination of the optimal sizes of stocks and periodicity of delivery to enterprises, working in the conditions of free market, accompanied by practical examples of application, are given in academic books [1-3, 5], scientific papers [4, 13-15]. It is absolutely evident that commercial service centres try to work with minimally possible terms of requests and supplies. The best representatives of service centres in the Western Siberian region work on the contract basis with periodicity of supplies of 6 days, based on urgent tariffs -3 days. At that, the periodicity of requests can amount to 2-6 times a week. But some suppliers introduce limitations by the size of the consignment. When considering 15-day delay of payments by the majority of contracts, the commercial service centres manage to increase their effectiveness practically without withdrawing financial resources from the circulation, meant for purchasing spare parts.

Discourses about periodicity of requests and supplies are by no means idle in case of resource provision of the $\mathrm{BV}$ operation in the oil-and-gas sector. For instance, quarterly purchase of spare parts in contrast to yearly reduces the volume of withdrawn financial resources from circulation on average 4 times. If the effect is calculated by the key refinancing rate of the Central Bank of the Russian Federation (RF), which is $-9 \%$, it can be calculated as a sum of quarterly effects. Monthly purchase and supply of spare parts will reduce the estimated expenditures on crediting 12 times in comparison with yearly.

Further, it is necessary to note that the purchasing procedure at enterprises with state financing, which are presented by major oil-and-gas companies of RF, has a number of limitations, related to observance of laws on purchases [9], as well as obeying corporative regularities [10]. In view of these limitations until recently, periodicity of spare parts purchases for SV of oil-and-gas companies has amounted to 1 year. This is extremely ineffective. And the point is not only in enormous financial resources, withdrawn from the circulation. The second constituent of the economy when reducing the purchasing period reducing the volume of unmarketable goods in the warehouses of enterprises. With periodicity of supply of 1 year, about $70 \%$ of unmarketable goods are accumulated in the warehouses. With the reduction of periodicity of supply up to 1 month, the volume of unmarketable goods reduces to $10 \%$ of the volume of purchase. Such situation is connected with the complexity of predicting the volume of works by the kinds of machinery. With monthly periodicity of supply, it is necessary to predict the operating time per unit of machinery from 1 to $3 \mathrm{MS}$. When predicting for the year - 12-36 MS. The accompanying replacements present the main problem when predicting.

Nevertheless, oil-and-gas companies have found the way out of the existing situation. Contracts on supply of spare parts are concluded for a year with monthly division by the nomenclature and the number, and with monthly payment after supply. The real term of spare parts supply in accordance with corporative regularities is impossible to realise quicker than for 50 days with periodicity of requests of 30 days [10]. The limit of the immediacy of purchases, for which it is necessary to strive in the oil-and-gas sector, can be determined based on the analysis of work of the commercial service centres in large settlements of the Western Siberian region.

The third constituent of economy when reducing the purchasing period is the required volume of storage in the warehouse. With quarterly supply, it reduces 4 times, with monthly - 12 times. Complete denial of warehouse areas and equipment is possible under condition of guaranteed supply of nomenclature of spare parts by the contractor immediately to the place and in time of MS and R.

Among negative moments of increasing the frequency of purchase, there is an increase of expenditures on conducting purchasing operations. However, these expenditures in conditions of oil-and-gas enterprises can be considered as conditionally unchangeable since the increase of the frequency and labour intensity of request operations is levelled by redistribution of the functional inside the enterprise.

One more constituent, which changes when periodicity of supply changes, is delivering parts to the place of installation on the vehicle. The peculiarity of the oil-and-gas sector is presence of remote hard-to-reach areas of machinery operation. There is a frequently applied scheme when the contractor organises delivery of spare parts to the main base of the enterprise, and then parts are delivered to PO in the deposit by the transport of the enterprise. On the whole, when calculating effectiveness, this constituent can be assumed as constant since periodicity of trips due to different technological needs to the PTB elements, located in PO, including the changeover, etc., occurs more frequently than once per month.

Proceeding from the mentioned reasoning, one should strive for minimally possible periodicity of spare parts supply (Figure 4). 


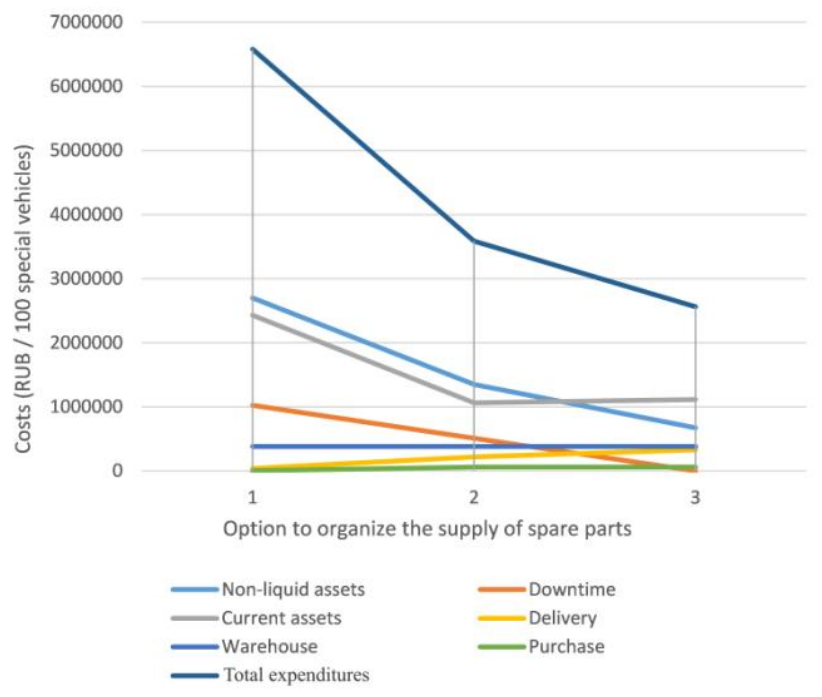

Fig. 4. Dependence of expenditures on variants of organisation of spare parts supply

From these considerations, using expression 1, a total effect for the TTC NGO enterprises from applying the suggested approach is calculated. It is calculated with consideration of shortening periodicity of supply of spare parts from 1 year (variant 1 of Figure 4) to 50 days with 30day periodicity of requests (variant 2), and to 30-day periodicity of requests and supplies (variant 3) per $100 \mathrm{SV}$.

\section{CONCLUSION}

The approach proposed in the paper allows optimizing the distribution of PSA among PTB elements. At that, key moments are the failure rate and the machinery exploitation intensity. The accuracy of predicting depends namely on these indicators. The methodology can be easily used by those enterprises where long-term observations after machinery failures and consumption of spare parts are conducted. As the mentioned considerations show, an essential factor influencing the accuracy of predicting the operating time by the kinds of machinery is a predicting period and, correspondingly, periodicity of formation of requests and supplies. The obtainment of an essential effect in managing the logistics of $\mathrm{TI}$ in maintaining and restoration of $\mathrm{SV}$ in $\mathrm{NGO}$ is possible only during simultaneous work on perfection of the methodology of accumulation and processing the information about failures of PSA, perfection of the methodology of predicting the exploitation intensity depending on production, natural and climatic factors.

Subsequent studies in this direction can be aimed at formation of the expert base on reliability of key kinds of machinery, limiting the reliability and safety of production processes in the oil-and-gas sector.

The best prospects in raising the level of machinery reliability, accuracy of predicting necessary nomenclature of resources can be provided by personified record of exploitation intensity, failure rates and consumptions by each vehicle [11] with entrance into the motivation system of the contractors.

\section{References}

[1] A.M. Gadzhinskiy, Practical work in logistics, Moscow, 2016.

[2] A.M. Gadzhinskiy, Designing of commodity distribution based on logistics, Moscow, 2013.

[3] A.M. Gadzhinskiy, Logistics. Manual for Bachelors, Moscow, 2014

[4] E.R. Dobronravin, A.N. Sterlingova, "Content and use of index of logistic profitability in work of trading enterprise", Logistics and management of supply chains, № 5, p. 38-44, 2010.

[5] A.N. Sterlingova, Logistics and management of supply chains Training manual for MBA students majoring in "General and strategic management", Moscow, 2008. Ser. Crede expert, State univers. of High economic school and High management school.

[6] N.S. Zakharov, Influence of seasonal conditions on the processes of quality changes of automobiles. Abstract of a thesis for a degree of Doctor of Science, Tyumen State Oil-and gas University, Tyumen, 2000.

[7] N.S. Zakharov, R.A. Ziganshin, A.V. Ziganshina, "Research of antiscuff properties all-seasonal motor and transmission oils", In proceeding: Transport and technological systems. Materials of international scientific and technical conference. Editor in chief N.S. Zakharov, 2015, p. 108-112

[8] N.S. Zakharov, O.A. Novoselov, R.A. Zaganshin, A.N. Makarova, "Structure of system when modelling consumption of spare parts for transport and technological vehicles in oil-and-gas industry", Scientific and engineering herald of Volga region, № 5, p. 193-195, 2014.

[9] Federal Law of 18 July 2011, N 223-FL "Concerning purchases of goods, works, services by separate legal". System GARANT: http://base.garant.ru/12188083/\#block_1\#ixzz4nlkd0IDJ

[10] Arrangement of supply of spare parts for transport vehicles and special machinery of the organisations of the system «Transneft» through consignment warehouses, Branch regulation, Moscow, 2014.

[11] V.I. Bauer, E.S. Kozin, A.V. Bazanov, "Methodology of determination of standard of spare parts for automotive engineering. In proceeding: Oil and gas of Western Siberia", Materials of scientific and technical conference devoted to 90-anniversary of birth of Kosukhin Anatoliy Nikolaevich, 2015, p. 148-152.

[12] A.V. Bazanov, E.S. Kozin, V.I. Bauer, "Problem of providing vehicle enterprises of oil pipeline branch with spare parts in Western Siberia”, Intellect. Innovations. Investments, № 4, p. 131-134, 2015.

[13] V.M. Terskikh, Optimisation and management of spare parts warehouse on enterprises exploiting and servicing MTS. Abstract of a thesis for a degree of Doctor of Science, Krasnoyarsk ,2016, p. 20.

[14] R.B. Chase, F.R. Jakobs, N.D. Aquilano Production and operational management, 2007. 